Article

\title{
Will the Use of Contextual Indicators Make UK Higher Education Admissions Fairer?
}

\author{
Vikki Boliver, Stephen Gorard * and Nadia Siddiqui \\ School of Education, Durham University, Leazes Road, Durham DH1 1TA, UK; \\ E-Mails: vikki.boliver@durham.ac.uk (V.B.); nadia.siddiqui@durham.ac.uk (N.S.) \\ * Author to whom correspondence should be addressed; E-Mail: s.a.c.gorard@durham.ac.uk; \\ Tel.: +44-191-334-8419.
}

Academic Editors: Anna Vignoles and Neil Murray

Received: 14 September 2015 / Accepted: 16 November 2015 / Published: 20 November 2015

\begin{abstract}
In the UK, as elsewhere, the use of 'contextual' data has been strongly advocated in order to inform undergraduate admissions decision-making. More than a third of UK universities currently take the socioeconomic or other background context of undergraduate applicants' attainment into account when deciding whom to shortlist, interview, make standard or reduced offers to, or accept at confirmation or clearing. Even more universities plan to do so in the future. Contextualised admissions policies are considered by many commentators to be intrinsically fairer, and to represent a potentially powerful means of addressing the persistent under-representation of HE students from less advantaged backgrounds, but their impact has not yet been rigorously evaluated. In order to be effective, the indicators must be accurate, appropriate, and complete, and policies for their use must demonstrably widen participation, presumably without compromising student achievement. This paper reviews the indicators available for judging context, and the existing evidence base on how contextually-identified students perform in higher education. It illustrates the considerable difficulties of using any available indicators, alone or in combination, in terms of trustworthiness. And it explains how their use could introduce new injustices while tackling merely the symptoms of stratified participation in HE. This is far from a counsel of despair. We need to widen participation and the use of context stills shows considerable promise. The paper therefore presents the case for a new
\end{abstract}


study by the authors, looking at which of the available contextual indicators are best in practice, and what difference their use would really make to widening participation at HE.

Keywords: Higher education; admissions; contextual admissions; overcoming disadvantage; social justice; indicators

\section{Introduction}

Students from less advantaged social and economic backgrounds are under-represented in UK higher education institutions, especially in the UK's most selective universities and in subjects leading to the professions [1-6]. The situation is similar in most countries for which data is available $[7,8]$. Despite differences in terminology and the precise nature of available indicators of disadvantage, the findings of this paper will be relevant to all such countries seeking to widen participation in a fair and appropriate manner.

The patterns of unequal access in the UK have not changed much since the 1960s, despite two major waves of higher education expansion in the 1960s and 1990s [9]. The Russell Group universities are considered by many to be the most prestigious in the UK, and their intakes are disproportionately students from fee-paying schools with high prior qualification levels [10]. Prior qualifications are important here, since differences between socioeconomic groups in rates of entry to high status universities have been found to be small after prior attainment has been taken into account. In fact, there was little or no difference between attendance rates for state and private schools. This implies that any under-representation is not necessarily of potential students with identical prior qualifications. Rather, students from less advantaged backgrounds are under-represented at least partly because their prior qualifications are lower on average.

In recent years, contextual data has been widely advocated as a means of addressing this, and a potentially fruitful way of widening participation in higher education [11-19]. The Department for Business, Innovation and Skills, the Office for Fair Access, and the Scottish Funding Council have begun formally encouraging (though not requiring) universities to use contextual data to inform undergraduate admissions decisions [4,19,20]. More than a third of UK universities now take into account the socio-economic context of applicants' attainment when deciding whom to shortlist, interview, make standard or reduced offers to, or accept at confirmation as "near-misses" [21], and over half of all universities state that they plan to use contextual data in admissions in the future [22].

The idea behind the use of contextual data in university admissions is that "it is fair and appropriate to consider contextual factors as well as formal educational achievement, given the variation in learners' opportunities and circumstances" [23] (p. 7); [24]. Such contextually sensitive use of data available for admissions has long been used with some apparent success in the USA, especially in respect of the "race" of the applicant [25], and their minority ethnic and language origin [26].

Contextual admissions policies typically involve the use of additional information about students' background characteristics such as the overall performance of their school and socio-economic markers which are linked with students' academic achievement. The value of contextual admissions policies as widening participation tools is that, in theory at least, they can help universities identify a 
"potential to succeed" in applicants whose formal attainment, relative to others, does not necessarily do justice to their true ability.

This is important given the persistent achievement gap at GCSE (typical qualification at age 16) and A-level (typical qualification at age 18) between students from higher and lower socioeconomic backgrounds, and given the fact that rates of attendance at high status universities have been found to be similar for different socioeconomic groups with ostensibly the same levels of prior attainment [10]. Previous research focusing specifically on university admissions suggests that applicants from lower social class backgrounds, non-selective state schools, low HE participation neighbourhoods, and some ethnic minority groups are in fact less likely to be offered places on university courses than their more advantaged peers with the levels of same prior attainment, especially at prestigious universities [27-31]. A further advantage of good contextual admissions policies, then, could be that contextually indicated applicants are looked at more carefully by admissions selectors.

Although contextualised admissions policies represent a potentially powerful means of making access to higher education fairer, not much is yet known about the quality of the indicators, or the implications of their use in undergraduate admissions on widening participation and student achievement. The independent body Supporting Professionalism in Admissions has emphasised the importance of using indicators of context that are both valid and reliable [18,22]. However, universities remain uncertain about which indicators to use, and continue to express concerns about the quality of the contextual data available to them [32], including the reliability of individual-level indicators of context where these are self-declared by applicants and unverified, and the validity of administratively verified neighbourhood-level and school-level contextual data given that these may not accurately reflect individual circumstances. Missing data creates further problems when universities are seeking to establish whether or not an applicant should be counted as coming from a disadvantaged context [33].

Government guidance on the use of contextual data in undergraduate admissions has stressed the need for policies and practices to be "fair, transparent, and evidence-based" [4] (p. 6); [19,20]. However, according to Supporting Professionalism in Admissions their case studies with selected universities have shown that the universities involved currently declare their WP policy and also the indicators they may use, but that any specific approach or protocol adopted during the selection process and applicant interviews remain undeclared [22]. Few universities seem to reference research evidence to support their contextual admissions policies, and the existing evidence base is generally anyway weak, piecemeal, and complex, as we discuss further below. The process of selection on contextual indicators is largely dependent on "tutors' professional judgment". This will presumably always be so, but using misleading or unreliable indicators to inform that judgement will tend to make the outcomes worse. However they are used, it is important to know more about the strengths and limitations of the available indicators of disadvantage.

\section{What are the Available Indicators? A Brief Overview}

Some studies have examined the relevance and impact of non-cognitive contextual variables that may help explain students' differential progress in the US [34], such as resilience in Spanish HE [35] and in the European Higher Education Area more generally [36]. However, none of these factors is of 
any current practical use since even where such variables can be measured accurately, the results will not be available to universities when making decisions about applicants. Universities could, of course, make all applicants complete a psychometric test but, this would expensive and impractical at present.

Common indicators of contextual admissions encompass individual-level, neighbourhood-level, and school-level measures of relative disadvantage. In the UK, individual-level indicators include low parental occupational or social class, low parental income, being first in the family to go to university, eligibility for free school meals, eligibility for an Education Maintenance Allowance (EMA, discontinued in England since 2010), attending a (non-selective) state-funded school, looked after status exceeding three months, identified as a traveller, identified as a refugee or asylum seeker, and identified as having a disability or special need. Some of these indicators are based on self-declarations and so contain a significant amount of missing data due to non-response and are unverified, resulting in questionable validity. Key exceptions are school type, free school meal eligibility (FSM), SEN status, and EMA eligibility in Scotland, Wales, and Northern Ireland. Even here though, there are major problems as we illustrate later in the paper by looking at FSM in more detail.

Neighbourhood-level indicators of context are based on students' home postcodes and identify students who live in an economically deprived area, in areas where many residents are from low socioeconomic groups, in an area characterised by a low rate of participation in higher education, or in a rural area. These measures are likely to be more valid than self-declared and unverified individual-level indicators, but may be unreliable indicators of the circumstances of specific individuals. It is an "ecological fallacy" to assume that people have the modal characteristics of those who live in the same area (or attend the same school, of course). Anyway, most of these area-level indicators are based on the aggregation of self-reports (via the Census of Population, for example), and actually have more missing data than the individual indicators.

School-level measures of context, based on the educational institution currently or previously attended, are of two kinds. One set includes aggregated socioeconomic indicators such as the percentage of students eligible for free school meals in each school. These too may be unreliable indicators of the circumstances of specific individuals, and have the same problems of individual measures in aggregate form, but are at least officially verified measures. The other set of school-level contextual variables refer to aggregated academic performance indicators. These may be expressed in absolute terms, for instance as the average GCSE or A-level (and equivalent) point score of pupils in the school, or the percentage of pupils in the school who go on to higher education. Alternatively they may be expressed in relative terms, such as whether or not the pupil's own performance is above average for their school.

Students are typically flagged-up as 'widening participation' applicants on one or multiple indicators of disadvantage. Universities may also flag up students who have participated in their outreach schemes, selection into these schemes usually having been based on a mixture of school-level contextual indicators. Information from a university applicant's personal statement or the teacher reference submitted with their application may also be used [21]. SPA has discussed how the use of multiple indicators can help institutions to hone in on those most applicants likely to be disadvantaged (reducing the number of false positives). Multiple indicators may also serve to hone in on those who suffer the most severe disadvantage (focusing attention where the need is greatest), a downside of 
which may be a significant number of false negatives. Published information about contextual indicators that universities are using for WP initiatives is available for only very few universities.

\section{How Robust are Contextual Admissions Indicators? Free School Meals as an Example}

There is insufficient space to describe the pros and cons of all possible contextual indicators here. Instead, we focus on one of the most promising in detail before drawing lessons about indicators more generally.

\subsection{The Clear Advantages of FSM}

In the UK, eligibility for free schools meals (FSM) is a valuable and widely-used measure of socio-economic background. In England (the most populous of the home countries of the UK), it denotes a child or young person of school age coming from a family or household deemed to be living below the relative poverty line. In practice this refers to any family entitled to income support, incomebased jobseekers allowance, child tax credit, the first four weeks of working tax credit following unemployment, the guaranteed element of state pension credit, employment and support allowance, and/or where part VI of the Immigration and Asylum Act 1999 applies. It is well-known and long-established that the 15\% or so FSM-eligible pupils in England have lower levels of attainment at school, on average, and are less likely to continue to post-compulsory education or training, including higher education [33].

FSM is already widely used in policy and practice in the UK. In England, it influences the level of generic funding for many schools, and forms the main basis on which additional pupil premium (PP) funding is allocated to schools. It is used, therefore, to create a pupil premium attainment gap by which school performance is monitored. This gap is the difference in attainment between pupils for whom the school receives the premium and the rest. FSM/PP is already an important contextual variable used by the inspection regime OFSTED when conducting statutory inspections of schools, for example. FSM is therefore a suitable candidate for being a contextual variable for admission to higher education - a measure of SES disadvantage that is strongly linked to attainment and progress in education.

FSM has many advantages as an indicator of SES background, compared to ethnicity or parental occupational class, for example. It has a clear legal definition in which a child either is or is not FSM-eligible. The inter-rater reliability for judging FSM-eligibility when in possession of the relevant information about the benefits listed above would be very high. The chief criterion-income supporthas not changed for decades, meaning that figures are reasonably comparable over time. Recording and reporting of it is a legal requirement for all state-funded schools, and the FSM-status of each child is held as part of the National Pupil Database (NPD) to which higher education institutions, or UCAS (the admissions service) itself, could have annual access. The measure is therefore available for all relevant young people, irrespective of whether that person applies to higher education or not. Perhaps most crucially, there are national school population figures going back decades showing the extent to which FSM-eligible pupils attain lower average qualifications than their peers. For all of these reasons it would probably be the single best measure of context currently available to HEIs when making a decision about each application. 


\subsection{The Unintended Consequences of Using FSM as Context}

This does not make FSM the right measure to use, in the sense of what we would devise if we could. It is merely among the best of those actually available. It would still require considerable work, of the kind that we are undertaking (see below), to ensure that its use would create more justice than the injustices it would inevitably introduce. For example, the welfare system provides more generous assistance to the poorest in society, and the benefits include all of those listed above, and many more including FSM itself which is of course a benefit before being a measure of SES. Those families with incomes just above the threshold for FSM do not receive these benefits, at least not to the same extent. Once all of the benefits are taken into account, this means that some of those families eligible for FSM end up with higher incomes than some families not deemed eligible [37]. If the concern is for family income, favouring only FSM-eligible pupils will exclude some of the poorer families simply because, at present, there is no way of identifying them. This could be deemed unfair-involving a new kind of unfairness that does not exist at present. Similar kinds of inequity would arise from the use of any indicator based either on a threshold, as here, or a judgement or self-report.

Even more obviously, there will be relevant data missing on some of the cases in any dataset. In the NPD for England, all available contextual variables are missing something like 10 to $13 \%$ of their pupil values every year [38]. A large proportion of these missing cases are accounted for by fee-paying schools which do not have to complete the full school census that state-funded schools do, but whose examination results are part of the database. To some extent, it can be argued that the 6 to $7 \%$ of the school population not in state-funded education are not relevant to an assessment of context for admission to HE. Most school fees will be paid for by their families who are therefore very unlikely to be living in relative poverty. However, before moving on to focus on the missing $4 \%$ in state schools, it is worth considering those outside the state system a little more.

A small number of children will be home-schooled or otherwise simply missing from the register, rather than in fee-paying schools. Some of these can be assumed to be among the poorest in society. Of the 6 to 7\% actually in fee-paying schools, a small number will also be among the poorest in society, and attending via a free place, bursary, scholarship, or assisted place. Some fee-paying schools are registered as charities and in recent years, since the demise of the state-sponsored Assisted Places Scheme, the Charity Commission has been pushing these schools to take their charitable status more seriously. One way in which these schools have reacted is by taking more pupils on free places from poorer backgrounds. It would make nonsense of this policy if it then clashed with the use of school type as a contextual indicator.

It is also the case that some very small private schools have only nominal fees, and serve some of the poorest communities in the UK [39]. The number of all such pupils from genuinely poor families will still be small, but they would all be ignored in any process using FSM-eligibility as a criterion for contextualised admission to HE. They and the home-schooled would actually be worse off than currently since their place at any university would be slightly more likely to be taken by a student who had been known to be FSM-eligible (even though there is a small chance that their family might have had a higher income overall).

More importantly, the remaining $4 \%$ of pupils missing data on FSM-eligibility in state-funded schools would also be ignored and so disadvantaged by a system that used FSM as a context variable 
for HE admissions. It has been shown from what we do know about these pupils is that they could be among the most disadvantaged in society [40]. They take fewer public examinations than FSM pupils, and are generally the least qualified students in the country. Leaving them out of a process that is intended to improve conditions for people just like them would be unjust. They are already treated unfairly (inadvertently). Their schools do not receive their full pupil premium funding (because the pupils are not known to be FSM-eligible), and their schools are disadvantaged in school performance figures and OFSTED inspections that use contextualised figures, and in their apparent PP attainment gap.

All of the latter three issues can affect school reputation and so which families use that school. This influences the mix of students that poorer pupils have as their peers. Who one goes to school with, especially for poorer children, could be important for a number of outcomes - including attainment [41], emotional and behavioural problems [42], the nature of relationships with teachers [43], aspirations [44], and so whether one continues to participate in education once it becomes post-compulsory [45]. Pupils from families in poverty but who are not known to be FSM-eligible are therefore doubly-disadvantaged. Using FSM for HE admissions as well would make that disadvantage considerably worse for this crucial minority.

A reasonable proportion of the young people missing data on their FSM-eligibility are in special schools (while many of the rest are mobile pupils such as Travellers, or recent arrivals such as asylum-seekers perhaps without official papers). Given the level of inclusion of children with special needs in mainstream settings, those in special schools are more often those with very severe learning and other challenges. All of these groups - SEN, Travellers, and asylum-seekers - could be among the most deserving of consideration in a contexualised admissions system, yet all would be ignored if they were missing FSM data, and FSM-eligibilty were a criterion used in admissions.

Of course, the irony is that none of this may matter for children from the most disadvantaged families who may not want to attend HE, and who may be so far from attaining the necessary prior qualifications that their inclusion would currently be unthinkable. The latter would include some children with the most serious learning challenges. Widening participation is currently aimed at the "usual suspects" of those most like existing and prior participants [44]. This would remain true if context were used to drop a few grade or point requirements for admissions. It would have little or no impact on those outside the mainstream system.

It is important to note that FSM-eligibility is not a permanent characteristic for any individual. If eligibility at the time of application to HE were used, then this would ignore what Noden and West [46] (p. 4) termed a 'hidden poor' of those pupils previously eligible for FSM but not subsequently. Such pupils may still be suffering the impacts of earlier disadvantage. Partly for this kind of reason, the Department for Education in England now produces a measure 'EverFSM6', included in the NPD, which covers pupils both currently and previously eligible for FSM over the last six years, and this is what is now used for PP calculations. However, Treadaway [47] considers that even this may not be enough. EverFSM6 still ignores pupils in secondary school who had been eligible more than six years previously. This further "invisible" group has attainment results that are in some ways more similar to the EverFSM6 pupils than those who have never been eligible.

On the other hand, giving an equal advantage in admissions to all applicants who had ever been eligible for FSM would not be fair for those from the poorest families. FSM-eligibility is only a threshold characteristic. Some individuals will be from families only just below the income threshold 
while others will be permanently below it. Some will have trajectories of moving in an out of FSM, while others will not. Some of this will be due to differences and changes in personal circumstances. Some will be what studies of the Assisted Places Scheme called the "artificially poor", or due to reasons of diet and religious observance [48]. Some will be sensitive to variations in the national or global economy, or to changes in the incentives for registering as FSM-eligible or for schools to collect accurate information about it. This matters because there is a hierarchy of poverty "effects". Those currently eligible for FSM but not previously, or previously but not now, are in many respects more like those not eligible at all than those permanently poor [49]. This is true of their other background characteristics like their ethnic origin and SEN status, and their attainment at school [50]. Those permanently eligible are the most disadvantaged, meaning that using EverFSM as a context variable would continue to be unfair to them.

Above all, the link between FSM and attainment or subsequent participation is only a correlation. Many FSM-eligible students enter HE every year, but these may be disproportionately those who are near the threshold for FSM or who have moved in or out of eligibility over time. They may be those from schools where the pupil premium attainment gap is zero or even reversed (they do exist). If any of these are so then it is not clear that such students should receive an equal advantage to those permanently eligible or from schools with very large PP attainment gaps. The problem is that many of the lowest attaining pupils at schools, including a high proportion in relative poverty, will leave education early and not attain even the minimum requirements for HE, or otherwise simply not apply. Many may not be interested [51]. Adjusting the scores of those FSM-eligible students who do apply will not address any of these issues, and the PP gap in attainment used to justify such contextualised admissions would be misleading (since it would need to be re-calculated only on the basis of those who applied).

The situation for FSM, used as a detailed case for consideration here, looks bad. Its use will not solve the most serious problems (for those not even in a position to apply), will not help some of the most disadvantaged whose FSM status is unknown, and will create new unfairness (as described above). However, FSM remains one of the most comprehensive and accurate measures of SES available. All other potential indicators have exactly the same kinds of problems, and for many of them the problems are even worse.

\subsection{Other Feasible Indicators}

Social class background, based on the classification of parents' occupations, is another important characteristic in the sense that it shows consistent variation in individuals' attainment and progression in education, and is correlated to some extent with measures of income. However, it does not have a legal definition like FSM. Moreover, there are often many missing values — indeed, one of the largest social class groups applying for admission to HE in the UK is generally "none/not known". The underlying occupations are almost always self-reported, making it potentially highly unreliable. Its use to give an advantage in contextualised admissions would likely lead to a growth of self-reporting in those categories deemed disadvantaged by admissions tutors [3], and in any case every classification is notoriously hard to code, and has relatively low inter-rater reliability [52]. 
Ethnic origin is another important characteristic in the sense that it shows consistent variation in individuals' attainment and progression in education, and is correlated to some extent with measures of income and social class. However, it does not have a legal definition like FSM. It has a large and growing number of categories, with at least as many missing values in NPD as FSM does. Missing or "not known" is the largest ethnic minority classification in the UK population census. The classification is heavily dependent on the identification of sole ethnicities, with the mixed categories intended to be for a minority. However, it is hard to contend that there are any individuals who do not have a mixed ethnic origin of some kind. All of this does not make it a particularly reliable or valid indicator $[53,54]$. It is so difficult to define operationally that this can only be done by self-definition. Its use to give an advantage in contextualised admissions would therefore also inevitably lead to a growth of self-reporting in those categories deemed disadvantaged by admissions tutors [3].

Information about the type and intake of the school attended by each applicant also has limitations. It will contain copious missing data, as with all indicators. For example, it will be silent about those outside mainstream school settings, such as the home-schooled, and anyone otherwise not appearing in NPD such as those recently arrived from other countries, perhaps even other home countries. Using categories such as private (as opposed to state) schools conflates the major public schools with cheap (less than the price of a daily newspaper) small sectarian schools and so on.

\subsection{Aggregated Indicators}

Some analysts attempt to avoid these kinds of problems by eschewing individual characteristics, and instead of defining potential disadvantage in terms of the measures of disadvantage in the local area that each individual lives. This is supposed to mean that missing data for individuals does not occur, as long as their address is known. However, this approach has almost all of the problems discussed so far, and introduces some new and even more serious ones.

Like occupational class, measures of geographical deprivation, such as the Income Deprivation Affection Children Index (IDACI) used by the DfE, have problems of definition. It is not clear whose address is used, or which if there is more than one. Again, since it has no clear legal status (unlike FSM), as soon as it was used as context for admissions there would be an incentive for individuals to claim preferential "post-restante" addresses, as has happened already to some extent in school admission procedures [48]. Perhaps most importantly, the idea that individuals possess the modal characteristics of those living in their local area is obviously false, even if all addresses were valid. Using IDACI or similar as context would unfairly advantage many individuals with no particular disadvantage and so would tend to squeeze out all individuals more deserving of help, especially those who were among the poorest in their own areas. Finally, even the premise about less missing data is false. In NPD for England, for example, around 10\% of pupils have no address details - about the same proportion missing as for FSM and ethnicity. However, using an area figure like this does not just mean losing about $10 \%$ of cases as with the other variables, because even the $90 \%$ of cases with a valid address have a score that is based upon the aggregation of individuals that themselves have missing values. This means, in effect, that all IDACI scores contain missing data, even when the individual pupil has a valid address. Many of the same points can be made about using school-level information related to an individual, such as the level of poverty in their school. 
None of this means that the use of contextual variables in improving admissions is impossible or misguided. It means, however, that considerable thought needs to be given as to what the precise aims are and how to operationalise them with the greatest chance of success, and the least chance of introducing further problems. This is what the analysis in our new project will allow (see below).

\section{How do Contextually Indicated Students Fare Academically in Higher Education?}

So far, this paper has considered admissions to university. What does the evidence say about the performance of contextually-disadvantaged students once admitted?

\subsection{Individual Level}

At the individual level, students from lower income families are already known to be more likely to drop out of HE, although the difference has apparently reduced since the student fees reforms from 2006 [55]. Student background has been found to make little or no difference to the chances of achieving a first class degree once prior attainment has been accounted for [56], and the chances of lower income students achieving a first class degree appears to have increased from 1998 to 2008 [57]. More evidence is needed on other individual-level indicators besides family income, such as parental social class, parental education, and FSM status, and also on other degree outcomes, including dropout.

\subsection{Neighbourhood Level}

Focusing on area-level measures of context used in the UK, we conducted an electronic search of the literature for a rapid review. The sources were Web of Science, Google Scholar, ERIC, and Scopus. Clearly, this did not uncover all relevant studies (and we are seeking funding for a full systematic review). It identified 22 large scale UK studies exploring the degree performance of contextually-indicated students relative to that of non- contextually indicated students with comparable levels of prior attainment. Studies looking at course completion or early drop-out are much rarer and so are not considered in detail here, although the outcome is of course an important one to explore. Of the 22 studies reviewed, 11 focused on a single institution (four in Cambridge, three in Edinburgh, and one each in St Andrews, Oxford, Bristol, and Cardiff). One study focused on a single subject area (Economics). The general pattern of findings can be summarised fairly easily: school-level contextual indicators tend to be associated with better or at least comparable degree performances for students with equivalent levels of prior attainment whereas neighbourhood-level contextual indicators tend to be associated with comparable or poorer degree performances.

Four studies explored the effects of coming from a low HE participation neighbourhood. Most of these studies found degree outcomes to be no different for these students [58-62]. One study found these students to perform less well than comparably qualified students from neighbourhoods where more people engage in HE [63]. Three studies examined the effects of coming from a deprived neighbourhood and all three found this to be associated with poorer performance at degree level [58-60,63,64]. Even if they were valid, the overall picture suggests that using areal indicators of context does not lead to good outcomes. This in turn raises the issue of what universities are doing and could do better to support non-traditional students to achieve at degree level. 


\subsection{School Level}

School type is the most common kind of contextual indicator examined (16 studies). The majority of studies (12) found that non-selective state school students fared better at degree level than comparably qualified private school students [30,61,63,65-71]. A minority of studies (four) found no school type difference in degree achievement, but all of these were concerned only with students at Cambridge — a highly selective university [72-75].

It may be that school type differences are smaller among students with very high levels of prior attainment. This hypothesis is consistent with one other study which reported a narrower school type gap for students with the equivalent of AAA+ at A-level (HEFCE 2003), but is at odds with three other studies finding non-negligible school-type differences in degree outcomes which also focused on one highly selective university, namely Oxford [76], St Andrew's [65], and Bristol [61] respectively.

One study looked at the effects of coming from a school with a high percentage of free school meal recipients, which was found to be positively associated with degree performance after taking prior attainment into account [77]. Seven studies focused on students from poorer performing schools. Two found that the contextually indicated students did worse than expected $[67,78]$. Three found them to fare as well $[61,63,79]$, while three found them to do better on average than comparably qualified peers from schools with higher average levels of attainment $[65,75,78]$. This last study also found that degree achievement was very different for male as compared to female students.

Three studies, all focused on Edinburgh University, explored the effects of coming from a school with a low rate of progression to HE, with mixed results [58-60]. Among those with Scottish Highers (a typical qualification at age 18), students from schools with low HE progression rates performed no differently to comparably qualified peers from schools with a stronger tradition of sending students to university. However, among students with A-levels (typically from England), those from low HE progression schools performed worse at degree level. Two studies found that students whose achievement was higher than the average for their school performed better at degree level than comparably qualified peers whose prior attainment was lower than the average for their school $[63,67]$.

The patterns highlighted above suggest that school-level indicators might be useful for identifying "potential to succeed" that can be readily translated into degree success. Neighbourhood-level contextual indicators, in contrast, may be more likely to identify students who may need additional support to achieve their potential in HE, but this conclusion is somewhat impressionistic. Also yet to be clearly established is how different contextual indicators relate to one another (although Crawford and Greaves [72] have made a start in this area), and how contextual indicators interact with other student characteristics such as gender and ethnicity, or with course characteristics such as level of academic selectivity and academic discipline, to affect achievement at university.

\section{Conclusions}

At present, the situation for the use of contextual indicators in HE admissions is unsatisfactory. Not all universities and colleges use them, or to the same extent. Those who do, do so differently from each other as far as we can tell, and most simply do not report how they do it. There is no single indicator or basket of indicators that is clearly fit for purpose in terms of validity, completeness, lack of bias and no 
danger of introducing new but perhaps less visible inequities. The latter is important. HEIs must do more than treat the symptoms (such as "we are below quota in one category so we must admit more from that category regardless"). The solution must be to identify securely those individuals who appear to have lower grades in the prior qualifications due largely to earlier disadvantage. How is this possible?

Clearly, a programme of research is needed to answer three fundamental questions regarding the use of contextual data in undergraduate admissions. First and foremost, research is needed to examine the extent to which different individual-level, neighbourhood-level, and school-level contextual indicators are correlated and to identify which ones represent the most valid and reliable measures of the socioeconomic circumstances of individuals.

Second, much more systematic work needs to be done to determine how well different contextual indicators, singly and in combination, predict success at degree level for comparatively disadvantaged students. It will be important to determine which contextual indicators identify students who are likely to perform as well as or better than comparably qualified peers from more advantaged environments, and who may therefore warrant prioritisation for admission over more advantaged applicants with comparable or higher grades. However, it will also be important to establish which contextual indicators are associated with poorer performance at degree level relative to comparably qualified peers from more advantaged environments so that additional support can be given to such students to enable them to realise their potential fully. It will, of course, be necessary to explore how these patterns vary by degree subject area and academic entry requirements.

Third, we need to establish how much impact different contextual admissions policies can be expected to have on the goal of widening participation in higher education for the sector as a whole and for particular institutions and academic disciplines. As part of this, we will need to establish robust ways of measuring the actual impact of particular contextual admissions strategies on the socioeconomic make-up of the student body, so that universities can provide better evidence of the success of their contextual admissions policies at widening participation without compromising student achievement. We will begin to provide answers to these important questions in our next paper, based on our work for the Scottish Funding Council, and the ESRC (grant number ES/N01166X/1).

\section{Author Contributions}

Vikki Boliver and Stephen Gorard co-wrote much of the paper, based on work they were undertaking jointly. Nadia Siddiqui was involved in searching for literature and in drafting the relevant sections of the paper. All authors were involved in the final production of the paper.

\section{Conflicts of Interest}

The authors have no conflict of interest.

\section{References}

1. Connor, H.; Dewson, S.; Tyers, C.; Eccles, J.; Regan, J.; Aston, J. Social Class and Higher Education: Issues Affecting Decisions on Participation by Lower Social Class Groups; Report 267; Institute for Employment Studies: Brighton, UK, 2011. 
2. Sutton Trust. The missing 3000-State schools under-represented at leading universities. Available online: http://www.suttontrust.com/our-work/research/item/the-missing-3000/ (accessed on 3 September 2015).

3. Gorard, S.; Adnett, N.; May, H.; Slack, K.; Smith, E.; Thomas, L. Overcoming Barriers to HE; Trentham Books: Stoke-on-Trent, UK, 2007.

4. BIS. Analysis of Progression Rates for Young People in England by Free school Meal Receipt and School Type. 2011. Available online: https://www.gov.uk/government/statistics/highereduction-progression-rates-for-young-people-in-england-by-free-school-meal-receipt-and-schooltype (accessed on 3 September 2015).

5. Broecke, S. University rankings: Do they matter in the UK? Educ. Econ. 2015, 23, 137-161.

6. Boliver, V. Are there distinctive clusters of higher and lower status universities in the UK? Oxf. Rev. Educ. 2015, 41, 608-627.

7. Boliver, V. Exploring ethnic inequalities in admission to Russell Group universities. Sociology 2015, doi:10.1177/0038038515575859.

8. Murray, N.; Klinger, C. Aspirations, Access and Attainment in Widening Participation: International Perspectives and an Agenda for Change; Routledge: London, UK, 2013.

9. Boliver, V. Expansion, differentiation, and the persistence of social class inequalities in British higher education. High. Educ. 2011, 61, 229-242.

10. Chowdry, H.; Crawford, C.; Dearden, L.; Goodman, A.; Vignoles, A. Widening participation in higher education: Analysis using linked data. J. Roy. Stat. Soc. 2013, 176, 431-457.

11. Department for Business, Innovation and Skills. Students at the Heart of the System; BIS: London, UK, 2011.

12. Department for Business, Innovation and Skills. Guidance to the Director of Fair Access; BIS: London, UK, 2011.

13. Panel on Fair Access to the Professions. Unleashing Aspiration: The Final Report of the Panel on Fair Access to the Professions. Available online: http://webarchive.nationalarchives.gov.uk/+/ http:/www.cabinetoffice.gov.uk/media/227102/fair-access.pdf (accessed on 3 September 2015).

14. Cabinet Office. Opening Doors, Breaking Down Barriers: A Strategy for Social Mobility; HMSO: London, UK, 2011.

15. Social Mobility and Child Poverty Commission. Higher Education: The Fair Access Challenge; HMSO: London, UK, 2013.

16. Social Mobility and Child Poverty Commission. State of the Nation: 2014 Report; HMSO: London, UK, 2014.

17. Social Mobility and Child Poverty Commission. University Challenge: How Higher Education Can Advance Social Mobility; HMSO: London, UK, 2012.

18. Supporting Professionalism in Admissions. Contextualised Admissions-Issues and Considerations for HE providers Introducing and Implementing Contextualised Admissions; SPA: Cheltenham, UK, 2014.

19. Office for Fair Access. OFFA Guidance on Preparing Access Agreements for 2014-2015; OFFA: Bristol, UK, 2013.

20. SFC. Learning for All: Measures of Success, Ninth Update; Scottish Funding Council: Edinburgh, UK, 2015. 
21. Moore, J.; Mountford-Zimdars, A.; Wiggans, J. Contextualised Admissions: Examining the Evidence; Supporting Professionalism in Admissions Programme: Cheltenham, UK, 2013.

22. SPA. Principles for the use of contextual data in admissions. Available online: www.spa.ac.uk/ (accessed on 3 September 2015)

23. Schwartz, S. Fair Admissions to Higher Education: Recommendations for Good Practice; HMSO: London, UK, 2004.

24. Universities UK. Fair Enough? Wider Access to University by Identifying Potential to Success; Universities UK: London, UK, 2003.

25. Bowen, W.; Bok, D. The Shape of the River: Long-Term Consequences of Considering Race in College and University Admissions; Princeton University Press: Princeton, NJ, USA, 1998.

26. Atkinson, R.; Pelfrey, P. Rethinking Admissions: US Public Universities in the Post-Affirmative Action Age; Research and Occasional Paper CSHE.11.04; University of California: Berkley, CA, USA, 2004.

27. Shiner, M.; Noden, P. 'Why are you applying there?': 'Race', class and the construction of higher education 'choice' in the United Kingdom. Br. J. Sociol. Educ. 2015, 36, 1170-1191.

28. Boliver, V. Widening Participation and Fair Access at the University of Oxford; Sociology Department Working Paper; Oxford University: Oxford, UK, 2004.

29. Boliver, V. How fair is access to more prestigious UK universities? Br. J. Sociol. 2013, 64, 344-364.

30. Zimdars, A.; Sullivan, A.; Heath, A. Elite higher education admissions in the arts and sciences. Sociology 2009, 43, 648-666.

31. Noden, P.; Shiner, M.; Modood, T. Black and Minority Ethnic Access to Higher Education A Reassessment; London School of Economics and Political Science: London, UK, 2014.

32. Bridger, K.; Shaw, J.; Moore, J. Fair Admissions to HE: Research to Describe the Use of Contextual Data in Admission at a Sample of Universities and Colleges in the UK; Supporting Professionalism in Admissions (SPA): Cheltenham, UK, 2015.

33. Gorard, S. An argument concerning overcoming inequalities in Higher Education. In Aspirations, Access and Attainment in Widening Participation: International Perspectives and an Agenda for Change; Murray, N., Klinger, C., Eds.; Routledge: London, UK, 2013.

34. West, M.; Kraft, M.; Finn, A.; Martin, R.; Duckworth, A.; Gabrieli, C.; Gabrieli, J. Promise and Paradox: Measuring Students' Non-cognitive Skills and the Impact of Schooling; Harvard Graduate School of Education: Cambridge, UK, 2014.

35. González-Torres, M.; Artuch-Garde, R. Resilience and coping strategy profiles at university: Contextual and demographic variables. Electron. J. Res. Educ. Psychol. 2014, 12, 621-648.

36. De la Fuente, J.; Cardelle-Elawar, M.; Martínez-Vicente, J.; Zapata, L.; Peralta, F. Gender as a determining factor in the coping strategies and resilience of university students. In Handbook of Academic Performance; Haumann R., Zimmer G., Eds.; Nova Science Publishers, Inc.: New York, NY, USA, 2013; pp. 205-217.

37. Hobbs, G.; Vignoles, A. Is children's free school meal 'eligibility' a good proxy for family income. Br. Educ. Res. J. 2010, 36, 673-690.

38. Gorard, S. Serious doubts about school effectiveness. Br. Educ. Res. J. 2010, 36, 735-766.

39. Gorard, S. School Choice in an Established Market; Ashgate: Aldershot, UK, 1997. 
40. Gorard, S. Who is eligible for free school meals? Characterising FSM as a measure of disadvantage in England. Br. Educ. Res. J. 2012, 38, 1003-1017.

41. Danhier, J.; Martin, E. Comparing compositional effects in two education systems: The case of the Belgian communities. Br. J. Educ. Stud. 2014, 62, 171-189.

42. Muller, M.; Hofmann, V. Does being assigned to a low school track negatively affect psychological adjustment? Sch. Effect. Sch. Improv. 2014, doi: 10.1080/09243453.2014.980277.

43. Vieluf, S.; Hochweber, J.; Klieme, E.; Kunter, M. Who has a good relationship with teachers? Oxf. Rev. Educ. 2015, 41, 3-25.

44. Gorard, S.; See, B.H. Overcoming Disadvantage in Education; Routledge: London, UK, 2013.

45. Palardy, G. High school socioeconomic segregation and student attainment. Am. Educ. Res. J. 2013, 50, 714-754.

46. Noden, P.; West, A. Attainment Gaps between the Most Deprived and Advantaged Schools; The Sutton Trust: London, UK, 2009.

47. Treadaway, M. Pupil Premium and the Invisible Group; FFT Research Paper No. 5; FFT Education Ltd.: Middlesbrough, UK, 2014.

48. Gorard, S.; Taylor, C.; Fitz, J. Schools, Markets and Choice Policies; RoutledgeFalmer: London, UK, 2003.

49. Crawford, C.; MacMillan, L.; Vignoles, A. Progress Made by High-attaining Children from Disadvantaged Backgrounds; Social Mobility and Child Poverty Commission: London, UK, 2014.

50. Gorard, S. A brief research note on measuring the pupil premium attainment gap in England. Available online: https://www.dur.ac.uk/resources/education/Pupilpremiumgap.pdf (accessed on 3 September 2015).

51. McMahon, S.; Harwood, V.; Hickey-Moody, A. Students that just hate school wouldn't go: Educationally disengaged and disadvantaged young people talk about university education. $B r . J$. Sociol. Educ. 2015, doi:10.1080/01425692.2015.1014546.

52. Lambert, P. Handling occupational information. Build. Res. Capacity 2002, 4, 9-12.

53. Gorard, S. Quantitative Methods in Social Science: The Role of Numbers Made Easy; Continuum: London, UK, 2003.

54. Lee, C. Why we need to re-think race and ethnicity in educational research. Educ. Res. 2003, 32, 3-5

55. Bradley, S.; Migali, G. The Effect of a Tuition Fee Reform on the Risk of Drop out from University in the UK; Working Paper; Lancaster University: Lancaster, UK, 2015.

56. Smith, E.; White, P. What makes a successful undergraduate? The relationship between student characteristics, degree subject and academic success at university. Br. Educ. Res. J. 2015, 41, 686-708.

57. Smith, E. Can higher education compensate for society? Modelling the determinants of academic success at university. Br. J. Sociol. Educ. 2015, doi:10.1080/01425692.2014.987728.

58. Croxford, L.; Doherty, G.; Gaukroger, R.; Hood, K. Widening Participation at the University of Edinburgh (1): Entry, Progression and Degree Outcomes of SQA-qualified Entrants; CES Ref 1221; Centre for Educational Sociology: Edinburgh, UK, 2013.

59. Croxford, L.; Doherty, G.; Gaukroger, R.; Hood, K. Widening Participation at the University of Edinburgh (2): Entry, Progression and Degree Outcomes of A-level Qualified Students; CES Ref 1302; Centre for Educational Sociology: Edinburgh, UK, 2013. 
60. Croxford, L.; Doherty, G.; Gaukroger, R.; Hood, K. Widening Participation at the University of Edinburgh (3): Entry, Progression and Degree Outcomes by Subject Area; CES Ref 1303; Centre for Educational Sociology: Edinburgh, UK, 2013.

61. Hoare, A.; Johnston, R. Widening participation through admissions policy-A British case study of school and university performance. Stud. High. Educ. 2011, 36, 21-41.

62. Taylor, T.; Rees, G.; Sloan, L.; Davies, R. Creating an inclusive higher education system? Progression and outcomes of students from low participation neighbourhoods at a Welsh university. Contemp. Wales 2013, 26, 138-161.

63. HEFCE. Differences in Degree Outcomes: Key Finding; HEFCE: Bristol, UK, 2014.

64. Crawford, C. The Link between Secondary School Characteristics and University Participation and Outcomes; Institute for Fiscal Studies: London, UK, 2014.

65. Lasselle, L.; McDougall-Bagnall, J.; Smith, I. School grades, school context and university degree performance: Evidence from an elite Scottish institution. Oxf. Rev. Educ. 2013, 40, 293-412.

66. McNabb, R.; Pal, S.; Sloane, P. Gender differences in educational attainment: The case of university students in England and Wales. Economica 2002, 69, 481-503.

67. Smith, J.; Naylor, R. Determinants of degree performance in UK universities: A statistical analysis of the 1993 student cohort. Oxf. Bull. Econ. Stat. 2001, 63, 29-60.

68. Smith, J.; Naylor, R. Schooling effects on subsequent university performance: Evidence for the UK university population. Econ. Educ. Rev. 2005, 24, 549-562.

69. Naylor, R.; Smith J. Degree performance of economics students in UK universities: Absolute and relative performance in prior qualifications. Scot. J. Polit. Econ. 2004, 51, 250-65.

70. Kirkup, C.; Wheater, R.; Morrison, J.; Durbin, B.; Pomati, M. Use of an Aptitude Test in University Entrance: A Validity Study; BIS Research Paper Number 26. 2010. Available online: https:/www.gov.uk/government/uploads/system/uploads/attachment_data/file/32423/10-1321use-of-aptitude-test-university-entrance-validity-study.pdf (accessed on 3 September 2015).

71. Crawford, C.; Greaves, E. A Comparison of Commonly Used Socio-economic Indicators: Their Relationship to Educational Disadvantage and Relevance to Teach First; Institute for Fiscal Studies: London, UK, 2013.

72. Chetwynd, P. Good Practice Statement Admission Policies; Supporting Professionalism in Admissions: Cheltenham, UK, 2014.

73. Sumnall, C. ANOVA on $\mathrm{A}^{*} \mathrm{~s}$ at A-level and tripos performance. Available online: http://www.admin.cam.ac.uk/offices/admissions/research/docs/Astar_Alevel_Tripos.pdf (accessed on 3 November 2015).

74. Partington, R.; Carroll, D.; Chetwynd, P. Predictive Effectiveness of Metrics in Admission to the University of Cambridge; University of Cambridge: Cambridge, UK, 2011.

75. Parks, G. Academic performance of undergraduate students at Cambridge by school/college background. Available online: http://www.admin.cam.ac.uk/offices/admissions/research/docs/ school_performance.pdf (accessed on 3 September 2015).

76. Ogg, T.; Zimdars, A.; Heath, A. Schooling effects on degree performance: A comparison of the predictive validity of aptitude testing and secondary school grades at Oxford University. $B r$. Educ.

Res. J. 2009, 35, 781-807. 
77. Crawford, C. Socio-economic Differences in University Outcomes in the UK: Drop-out, Degree Completion and Degree Class; Institute for Fiscal Studies: London, UK, 2014.

78. HEFCE. Schooling effects on higher education achievement HEFCE 2003/32. Available online: www.hefce.ac.uk/pubs/hefce/2003/03_32.htm (accessed on 3 September 2015).

79. Hammond, J.A.; Lewis, K.; White, H.; Bowman, D. Adjusting the academy: Developing an adjusted entrance criteria scheme in a specialist healthcare and bioscience higher education institution. Widening Participation Lifelong Learn. 2012, 13, 45-49.

(C) 2015 by the authors; licensee MDPI, Basel, Switzerland. This article is an open access article distributed under the terms and conditions of the Creative Commons Attribution license (http://creativecommons.org/licenses/by/4.0/). 